\title{
Survey of electronic properties and local structures around Fe in selected multinary chalcogenides
}

I. Radisavljevic ${ }^{a^{*}}$, N. Novakovića, H.-E. Mahnke ${ }^{\mathrm{b}}$, V. Andrić ${ }^{\mathrm{a}}$, S. Kurko ${ }^{\mathrm{a}}$, D. Milivojevića ${ }^{\mathrm{a}}$, N. Romčevićc and N. Ivanovićc

${ }^{a}$ University of Belgrade-Vinča Institute of Nuclear Sciences, P.O. Box 522, 11001 Belgrade, Serbia

${ }^{b}$ Helmholtz-Zentrum Berlin für Materialien und Energie GmbH, D-14109 Berlin, Germany ${ }^{c}$ University of Belgrade-Institute of Physics, Pregrevica 118, 11000 Belgrade, Serbia

Corresponding author: Tel.: +381 113408 254; Fax: +381 113440100 .

E-mail address: iva@vin.bg.ac.rs (I. Radisavljević)

\begin{abstract}
Paper presents detailed studies of local and electronic structure around $\mathrm{Fe}$ in $\mathrm{Cd}_{0.97} \mathrm{Fe}_{0.03} \mathrm{Te}$, $\mathrm{Cd}_{0.98} \mathrm{Fe}_{0.02} \mathrm{Te}_{0.97} \mathrm{Se}_{0.03}$ and $\mathrm{Cd}_{0.99} \mathrm{Fe}_{0.01} \mathrm{Te}_{0.91} \mathrm{~S}_{0.09}$ multinary chalcogenides by means of $\mathrm{X}$-ray absorption fine structure (XAFS), X-ray magnetic circular dichroism (XMCD) and electron paramagnetic resonance (EPR) measurements. In addition, electronic consequences of $\mathrm{Fe}$ incorporation into CdTe semiconductor host were studied by means of first principles calculations. In order to improve accuracy of the calculated total energies, the band gaps and the band edge positions, special attention is paid to the treatment of exchange-correlation interaction and the description of highly localized Fe 3d-states. Also, the Bader theory of the topological properties of the electron charge density is used to access details of the nature,
\end{abstract}


strength and distribution of the (next) nearest neighbour bonds. Local and electronic structure around $\mathrm{Fe}$ in $\mathrm{Cd}_{0.97} \mathrm{Fe}_{0.03} \mathrm{Te}$ and $\mathrm{Cd}_{0.98} \mathrm{Fe}_{0.02} \mathrm{Te}_{0.97} \mathrm{Se}_{0.03}$ systems have been found to exhibit similar characteristics, since the first coordination sphere around $\mathrm{Fe}$ comprises four Te atoms located at approximately the same distance. In $\mathrm{Cd}_{0.99} \mathrm{Fe}_{0.01} \mathrm{Te}_{0.91} \mathrm{~S}_{0.09}$ system, however, local bimodal distribution of distances has been revealed, with one Fe-Te bond replaced with much shorter Fe-S bond, resulting in much stronger crystal-field. Along with the crystal field effect, the spin-orbit interaction has proven to play decisive role in determining the nature of Fe doped CdTe systems. While the systems with higher Fe concentrations (25 at.\%) are intrinsic insulators, in systems with only 3.125 at.\% Fe one spin channel contributes to the density of states at the Fermi level, which makes them suitable for spin selective electronic transport applications.

Keywords: impurities in semiconductors; electronic properties; EXAFS; electronic band structure

\section{Introduction}

The wide band-gap semiconductors doped with transition metals (TM) attract scientific interest for a long time. The reasons for that are primarily lying in the possibility to exploit strong sp-d exchange interaction between the localized d-electrons of TM magnetic ions and sp-charge carriers of the host semiconductor [1,2] and that way to enable control and modification of electrical and optical properties by magnetic field (and vice versa). The unique combination of semiconducting and magnetic properties of a single material has outstanding potential for future spintronics applications [3-5]. Within this prospective research field huge efforts are being made in order to realize diluted magnetic semiconductors (DMSs), materials which can sustain ferromagnetic order above room 
temperature. In search for the room temperature ferromagnetism (RTFM) in DMSs [6-10] along with the most extensively studied Mn-based systems [3, 11-13], possibilities to utilize other TM impurities $(\mathrm{Fe}, \mathrm{Co}, \mathrm{Cr}, \ldots)$ in various wide band-gap semiconductor hosts are also being explored [6,14-18]. Iron-based DMSs are promising in this respect, with RTFM already achieved in a number of III-V [19,20], and II-VI semiconductor hosts [21-24]. Cadmium chalcogenides doped with Fe are convenient DMSs model systems for studying magnetic interaction, since $\mathrm{Fe}^{2+}$ ion possesses both spin and orbital momentum, which enables to study more general and more complex phenomena. Partial substitution of the chalcogen ion $(\mathrm{Ch})$ offers an additional possibility to tailor material properties (i.e. crystal structure, electronic and magnetic properties) $[13,25,26]$. The most striking effect of the Ch ion substitution can be seen in the new family of iron chalcogenide superconductors Fe(Te, Se, S) [27-29], where Te substitution by S promotes superconductivity in otherwise nonsuperconductive FeTe [28], whereas partial substitution of Se by Te increases superconducting temperature of FeSe [29]. Iron-based DMSs CdTe and CdSe display Van Vleck paramagnetism manifested in temperature-independent magnetic susceptibility at $\mathrm{T}<10 \mathrm{~K}[30]$. In the absence of magnetic field $\mathrm{Fe}^{2+}$ ions have no permanent magnetic moment due to nondegenerate ground energy level [24]. Studies of the atomic correlations in multinary $\mathrm{Cd}_{1-\mathrm{x}} \mathrm{Fe}_{\mathrm{x}} \mathrm{Te}_{1-\mathrm{y}}(\mathrm{Se}, \mathrm{S})_{\mathrm{y}}$ chalcogenides [13,25,31-35], revealed that as a result of nearest neighbor and site occupation preferences, a part of $\mathrm{Fe}^{2+}$ ions may be located in lowsymmetry crystal environments. Depending on the material composition and characteristics of the nearest neighbor $(\mathrm{NN})$ coordination, the ground state of $\mathrm{Fe}^{2+}$ ion can take several different positions in the band structure of the host material, and as a result physical properties of the material may be considerably affected. Given the enduring importance of the TM-doped multinary chalcogenides, in this paper we present detailed studies of local and electronic structure around $\mathrm{Fe}$ in $\mathrm{Cd}_{0.97} \mathrm{Fe}_{0.03} \mathrm{Te}, \mathrm{Cd}_{0.98} \mathrm{Fe}_{0.02} \mathrm{Te}_{0.97} \mathrm{Se}_{0.03}$ and 
$\mathrm{Cd}_{0.99} \mathrm{Fe}_{0.01} \mathrm{Te}_{0.91} \mathrm{~S}_{0.09}$ systems. The results obtained by means of the $\mathrm{X}$-ray absorption fine structure (XAFS), X-ray magnetic circular dichroism (XMCD) and electron paramagnetic resonance (EPR) measurements are complemented with the first principle electronic structure calculations and charge density topology analysis of Fe doped CdTe-systems.

\section{Experimental details}

Crystalline $\mathrm{Cd}_{0.97} \mathrm{Fe}_{0.03} \mathrm{Te}(\mathrm{CdFeTe}), \mathrm{Cd}_{0.98} \mathrm{Fe}_{0.02} \mathrm{Te}_{0.97} \mathrm{Se}_{0.03}(\mathrm{CdFeTeSe})$ and $\mathrm{Cd}_{0.99} \mathrm{Fe}_{0.01} \mathrm{Te}_{0.91} \mathrm{~S}_{0.09}(\mathrm{CdFeTeS})$ samples were grown by the Bridgman method at the Institute of Physics of the Polish Academy of Science (Warszawa, Poland). X-ray diffraction (XRD) measurements were performed on Siemens D5000 diffractometer with Ni filtered $\mathrm{Cu}-$ $\mathrm{K}_{\alpha 1,2}$ radiation in Bragg-Brentano geometry in the range of angles $10^{0}<2 \theta<90^{\circ}$ with step $0.02^{0}$ and acquisition time $2 \mathrm{~s} / \mathrm{step}$. Composition of the samples was checked by energy dispersive X-ray fluorescence (EDXRF) spectroscopy performed by an EDXRF Camberra spectrometer with an ${ }^{241} \mathrm{Am}\left({ }^{109} \mathrm{Cd}\right)$ excitation source and $\mathrm{Si}(\mathrm{Li})$ detector. The Fe K-edge extended XAFS (EXAFS) and X-ray near-edge absorption spectra (XANES) were collected at $77 \mathrm{~K}$ in fluorescence yield mode at the HASYLAB C1 beamline of Deutsches ElektronenSynchrotron DESY. The Fe $\mathrm{L}_{2,3}$-edge XANES measurements were performed at $80 \mathrm{~K}$ in total-electron yield mode at the CiPo Beamline of Elettra Synchrotron Radiation Facility (Trieste, Italy). Circularly polarized absorption spectra were measured in the external magnetic field $B=0.3 \mathrm{~T}$ applied perpendicular to the sample surface, with photon helicity $\rho^{+}$ (right-handed) and $\rho^{-}$(left-handed) reversed at each photon energy. Multiple scans were taken to improve signal-to-noise ratio. XAFS data processing and analysis were performed using ATHENA and ARTEMIS packages [36], according to the standard procedure described elsewhere [37]. In the fitting process the following parameters were varied: the mean distance 
of the $j-$ th shell $\left(R_{j}\right)$, the number of atoms in the $j-$ th shell $\left(N_{j}\right)$, the mean-squared displacement of atoms in the $\mathrm{j}$-the shell $\left(\sigma_{\mathrm{j}}^{2}\right)$ and the edge shift correction $\left(\Delta \mathrm{E}_{0}\right)$. Multiple $\Delta \mathrm{E}_{0}$ parameters were used to account for the errors in FEFF's phases, which might be element specific. The stability of each particular fit was tested both by changing k-weights of the EXAFS function $\chi(\mathrm{k})$ and by performing $\mathrm{k}-$ and $\mathrm{R}-$-space fitting. Electron paramagnetic resonance (EPR) experiments were performed at room temperature (RT) by X-band Magnet Tech MS300 spectrometer operating at nominal frequency of $9.5 \mathrm{GHz}$ and microwave power of $1 \mathrm{~mW}$ (microwave attenuation $20 \mathrm{~dB}$ ) with modulation amplitude of $0.2 \mathrm{mT}$.

\section{Theoretical calculations}

Electronic structure calculations were performed using linearized augmented plane wave method in full potential with addition of local orbitals (FP-(L)APW+lo), as implemented in WIEN2k code [38] (LAPW+lo method is used for $\mathrm{s}-$ and $\mathrm{p}-$-states, and APW+LO is used for d-states). Core states are treated fully relativistic, while valence states are treated within scalar relativistic approximation. All calculations have been performed with and without spin-polarization (SP) (the later corresponding to the non-magnetic situation) with direction of magnetization (001). The spin-orbit (SO) coupling was also enabled. Radii of nonoverlapping muffin-tin atomic spheres $\left(\mathrm{R}_{\mathrm{MT}}\right)$ were chosen to be $1.217 \AA$ for $\mathrm{Cd}$ and $\mathrm{Te}$, and $1.058 \AA$ for Fe. The size and completeness of the basis set is controlled via the $\mathrm{R}_{\mathrm{MT}} \mathrm{k}_{\max }$ parameter, which was set to 7.0. The cut-off value of the plane wave expansion of charge density outside the muffin-tin radii was defined using parameter $G_{\max }=14$. To improve determination of CdTe lattice constant, which is known to be greatly overestimated in both Local Density Approximation (LDA) and standard Generalized Gradient Approximation (GGA) methods [39], we have also used Wu and Cohen (WC) parametrization [40]. For more 
accurate description of highly localized Fe 3d states [41], and also in order to improve estimation of energy gaps $\left(\mathrm{E}_{\mathrm{g}}\right)$, GGA calculations were followed by GGA+U (U - Hubbard term which describes on site Coulomb interaction of localized electrons). Choice of the proper calculation method and the value of $U$ parameter is very important in order to get realistic picture for a given material (e.g. in LDA calculation Fe ions in II-VI compounds were found to exhibit anti-ferromagnetic coupling [32]). Besides, while the exchange coupling constants are independent of the concentration, strength of the superexchange (which usually promotes anti-ferromagnetism) strongly depends on U [32]. To choose optimal value of the effective Hubbard term $\left(\mathrm{U}_{\text {eff }}\right)$, a comparison is made between the calculated positions of the most prominent Fe 3d-peaks and the CdFeTe resonant photoemission spectra [42]. In that way we have found that $U_{\text {eff }}=2 \mathrm{eV}$ sufficiently well reproduces the positions of $\mathrm{Fe} 3 \mathrm{~d}-$-states in the valence band (VB). On the other side, to reproduce correct binding energy of the localized $\mathrm{Cd} 4 \mathrm{~d}-$-semicore states [43] unphysically large value $U_{\text {eff }}=12 \mathrm{eV}$ had to be used, but since these states were found to have negligible influence on the VB position and its width, the later correction was not taken into account in subsequent calculations. This observation is supported by the recent findings of MoralesGarcía et al. [44], which state that the problem of predicting band gaps from standard DFT calculation does not arise from intrinsic errors of the DFT method (e.g. incorrect binding energies of the localized d-semicore states of cations in II-VI semiconductors), but rather from the assignment of a physical meaning to the Kohn-Sham energy levels. It should be also noted that the accuracy in the cation d-band energy estimation still has not been completely achieved, even when more expensive computational methods based on hybrid functionals are employed [45]. 
Initial calculations were performed for pure CdTe with cubic zinc-blende (ZB) crystal structure, where each atom is tetrahedrally coordinated with four atoms of different kind. For the k-point sampling $72 \mathrm{k}$ points in irreducible part of Brillouin zone (BZ) were used $(2000 \mathrm{k}$ points in the entire BZ with $12 \times 12 \times 12$ grid sampling). The unit cell parameters obtained for pure $\mathrm{ZB}-\mathrm{CdTe}$ after full relaxation of atomic forces and the unit cell volume, were used as input parameters for calculations of two different model systems. The first model involves standard CdTe unit cell, where one $\mathrm{Cd}$ atom is replaced with Fe, giving 25 at.\% $\mathrm{Fe}$ concentration (model $\mathrm{Cd}_{3} \mathrm{FeTe}_{4}$ ). The second model involves supercell approach, with $2 \times 2 \times 2$ unit cells stacking and total of 64 atoms. Again, one $\mathrm{Cd}$ atom was substituted with Fe, giving the Fe concentration of only 3.125 at. $\%$ (model $\mathrm{Cd}_{31} \mathrm{FeTe}_{32}$ ). For $\mathrm{k}$-points sampling $72 \mathrm{k}$ points in IBZ were used for $\mathrm{Cd}_{3} \mathrm{FeTe}_{4}$, and $10 \mathrm{k}$ points in IBZ (300 k points in $\mathrm{BZ}$ ) were used for $\mathrm{Cd}_{31} \mathrm{FeTe}_{32}$ model system. The SO relativistic treatment of $\mathrm{Cd}$ and Te host atoms was introduced after forces had been being minimized below $0.5 \mathrm{mRyd} / \mathrm{a} . \mathrm{u}$. The overall symmetry is lowered when SO coupling is included and the required number of $\mathrm{k}$ points raises up to 216 in BZ for the same 12x12x12 k point sampling. While the unit cell volume optimization was performed for $\mathrm{Cd}_{3} \mathrm{FeTe}_{4}$, this was not the case for $\mathrm{Cd}_{31} \mathrm{FeTe}_{32}$, due to sheer size of supercell and under assumption that in the presence of dopant the relaxation of the structure is only local.

The Bader analysis method of the topological properties of the electron charge density [46], as implemented in the CRITIC2 code [47], is used to gain additional insights into details of bonding in $\mathrm{Cd}_{3} \mathrm{FeTe}_{4}$ model system. The separate analysis of topology and charge density scalar fields has been performed, in order to get access to charge and spin magnetic moment on Fe and surrounding host lattice ions. 


\section{Results and discussion}

X-ray diffractograms (XRD) of the CdFeTeSe and CdFeTeS are shown in Fig.1. All diffraction peaks are indexed using the single-phase ZB crystal structure, characteristic for the host CdTe compound. The EPR spectra of investigated samples measured with and without UV lamp are shown in Fig. 2. Absence of EPR signal in both regimes (see Fig. 2) implies that Fe ions are in $2+$ charge state.

\subsection{Fe K-edge EXAFS spectra}

The Fe K-edge EXAFS oscillations in k-space measured in samples CdFeTe, CdFeTeSe, and $\mathrm{CdFeTeS}$ at $\mathrm{T}=77 \mathrm{~K}$, and the corresponding Fourier transforms (FT) of the $\mathrm{k}^{2}$-weighted EXAFS functions $\mathrm{k}^{2} \chi(\mathrm{k})$ are presented in Fig. 3. Structural parameters obtained from the EXAFS data analysis, together with predicted bond valence sums [48], are summarized in Table 1. The Fe impurity incorporates preferably as a substitution into the cation $(\mathrm{Cd})$ site. In all investigated compounds the Fe-Te distances have nearly the same length $(2.671-2.684 \AA$, see Table 1), which is shorter than Cd-Te distance in binary CdTe compound (2.80 $\AA$ [49]), but almost exactly matches the sum of $\mathrm{Fe}$ and Te tetrahedral covalent radii [50,51]. The first coordination tetrahedron around $\mathrm{Fe}$ in $\mathrm{CdFeTeS}$ comprises three Te and one $\mathrm{S}$ atom (on average). The Fe-S distance (2.37 $\AA$, see Table 1) is also shorter than the Cd-S distance in binary CdS compound (2.525 $\mathrm{A})$, but again coincides with the sum of Fe and S tetrahedral covalent radii $[50,51]$. Local bimodal distribution of $\mathrm{Fe}-\mathrm{Ch}$ distances has been already observed in many ternary $\left(\mathrm{FeSe}_{1-\mathrm{x}} \mathrm{Te}_{\mathrm{x}}[52]\right)$ and quaternary $\left(\mathrm{Zn}_{1-\mathrm{x}} \mathrm{Fe}_{\mathrm{x}} \mathrm{Se}_{1-\mathrm{y}} \mathrm{Te}_{\mathrm{y}}[25]\right) \mathrm{Fe}-$ chalcogenides. However, in $\mathrm{Cd}_{1-\mathrm{x}} \mathrm{Fe}_{\mathrm{x}} \mathrm{Te}_{1-\mathrm{y}} \mathrm{Se}_{\mathrm{y}}$ system for the given molar fraction $(\mathrm{x}=0.02$, $\mathrm{y}=0.03$ at.\%) the majority of Fe ions are surrounded by four Te atoms. Indeed, Fe ions are 
expected to have at least one Se atom as the nearest neighbor starting from $\mathrm{y}=0.07$ at.\% [15]. Unlike $\mathrm{Cd}_{1-\mathrm{x}} \mathrm{Fe}_{\mathrm{x}} \mathrm{Te}_{1-\mathrm{y}} \mathrm{Se}_{\mathrm{y}}$ system, preferential pairing of minority components in $\mathrm{Cd}_{1-\mathrm{x}} \mathrm{Fe}_{\mathrm{x}} \mathrm{Te}_{1-}$ ${ }_{\mathrm{y}} \mathrm{S}_{\mathrm{y}}$ is observed also for lower $\mathrm{S}$ concentrations ( $\mathrm{y}=0.03$ at. \%) [35].

The NN-coordination of substitutional Fe impurity ideally has tetrahedral $\left(\mathrm{T}_{\mathrm{d}}\right)$ symmetry. However, presence of different $\mathrm{Ch}$ ions in immediate $\mathrm{Fe}$ surrounding (or unequal $\mathrm{Fe}-\mathrm{Ch}$ bond distribution in a homogenous $C$ environment) causes distortion of the $T_{d}$ crystal field and lowers the symmetry at the Fe ions' site [53]. Small disorder parameters in $\mathrm{CdFeTe}(\mathrm{Se})$ samples $\left(\sigma_{\mathrm{Fe}-\mathrm{Te}}^{2}=0.0021-0.0024 \AA^{2}\right.$, see Table 1) indicate that distortion of the Fe site is not appreciable. Moreover, only slightly contracted second (Fe-Cd) and third (Fe-Te) coordination distances as compared to $\mathrm{CdTe}$ (see Table 1) imply that $\mathrm{Fe}$-incorporation into CdTe lattice primarily affects the arrangement of atoms in its immediate surrounding. On the other side, in CdFeTeS sample $\mathrm{T}_{\mathrm{d}}$ symmetry of the Fe site is distorted due to the presence of $\mathrm{S}$. Even though both $\mathrm{Fe}-\mathrm{Te}$ distance and its disorder parameter $\sigma_{\mathrm{Fe}-\mathrm{Te}}^{2}$ remain close to the values obtained in other two samples (see Table 1), splitting of the second shell into two subshells (see Fig. 3), implies that the local structural distortion in CdFeTeS sample extends beyond the first coordination shell around Fe. Note that the mean value of the weighted FeCd distance (4.51 $\AA$, see Table 1) is close to the value obtained for other two samples.

\subsection{Fe K-edge XANES spectra}

Normalized Fe K-edge XANES spectra taken at $77 \mathrm{~K}$ shown in Fig. 4, result mainly from the transition of $1 \mathrm{~s}$ electrons into empty states with $\mathrm{p}$ character. However, in the absence of inversion center in $T_{d}$ symmetry, mixing between $\mathrm{Fe} 3 \mathrm{~d}$ and $4 \mathrm{p}$ levels is not only allowed but also it becomes significant. Dipole transitions from Fe 1s state to unoccupied $\mathrm{Fe}-3 \mathrm{~d} / \mathrm{Ch}-\mathrm{p}$ 
hybrid bands (including a substantial admixture of the quadrupole $1 \mathrm{~s} \rightarrow 3 \mathrm{~d}$ transitions) give rise to the intense pre-edge feature $a$, clearly resolved in all investigated samples (see Fig. 4). The $\mathrm{CdFeTe}(\mathrm{Se}) \mathrm{XANES}$ spectra share similar shape, with close absorption edge positions (feature $b$ ) and similar sharp white lines (feature $c$ ). In the absence of Se in the vicinity of $\mathrm{Fe}$, the conduction band $(\mathrm{CB})$ bottom (composed of $\mathrm{Te}-\mathrm{p} / \mathrm{Cd}-\mathrm{s}$ hybridized states, see Supplementary material for more details) is consequently at the same binding energy in both CdFeTe and CdFeTeSe samples. Similar spectral shapes imply that the local structure around $\mathrm{Fe}$ in $\mathrm{CdFeTe}(\mathrm{Se})$ is also similar, which confirms the obtained EXAFS results. The absorption edge of the CdFeTeS XANES spectrum is shifted to slightly higher energies with somewhat broader and less intense white line, thereby indicating lower symmetry at the $\mathrm{Fe}-$ site. According to the presented EXAFS results, the latter is a consequence of distorted tetrahedral coordination which comprises a mixture of $\mathrm{Fe}-\mathrm{Te}$ and $\mathrm{Fe}-\mathrm{S}$ bonds. Similar broadening and the shift of the white line in the $\mathrm{FeSe}_{0.5} \mathrm{Te}_{0.5}$ were ascribed to the local inhomogeneity of the system, characterized by coexistence of different $\mathrm{Fe}-\mathrm{Ch}$ bonds [54]. Furthermore, larger electronegativity of S (2.58) as compared to Te (2.1) implies that hybridized $\mathrm{Fe}-3 \mathrm{~d} / \mathrm{Ch}-\mathrm{p}$ states are placed at higher binding energies in $\mathrm{FeS}$ than in FeTe [55]. The Fe-3d/Te-5p hybridization is somewhat weaker (lower Fe-Te bond valence, see Table 1), which results in slightly longer Fe-Te distance. According to the bond valence sums (see Table 1), Fe is expected to use less electrons to form mixed bonds with Te and $\mathrm{S}$, than to form bonds only with $\mathrm{Te}$ (Fe ion is larger and less charged), which supports its preferences for paring with $\mathrm{S}$.

To gain more detailed information on Fe electronic structure and geometry of its NNcoordination, as well as the hybridization of the $\mathrm{Fe} 3 \mathrm{~d}$ and $\mathrm{Ch}$ p orbitals, the pre-edge region of the XANES spectra is inspected. In general, the structure of the XANES pre-edge feature 
for a given oxidation and spin state of the Fe ion is specified by the $\mathrm{T}_{\mathrm{d}}$ symmetry of its $\mathrm{NN}-$ coordination. However, distortions and existence of different $\mathrm{Fe}-\mathrm{Ch}$ bond lengths which lower the symmetry at the Fe site result in appearance of additional features in the pre-edge structure. Fig. 5 shows the pre-edge region of the experimental Fe K-edge XANES spectra enlarged. Similar symmetric shapes of the pre-edge structures in the $\mathrm{CdFeTe}(\mathrm{Se}) \mathrm{XANES}$ spectra (see Fig. 5) reflect similar Fe-local environments, which is according to EXAFS analysis almost exclusively composed of Te atoms. Irregularities of the $\mathrm{Fe} \mathrm{NN}$-coordination which increase the $\mathrm{Fe}-3 \mathrm{~d} / \mathrm{Ch}-\mathrm{p}$ orbital mixing [56] are especially pronounced in $\mathrm{CdFeTeS}$ sample, whose spectrum exhibits the most intense pre-edge feature. The shape of the preedge structure in this sample (see Fig. 5c) reflects bimodal distribution of Fe-Ch bonds [25]. Possible coexistence of differently charged $\mathrm{Fe}$ ions $\left(\mathrm{Fe}^{2+} / \mathrm{Fe}^{3+}\right)$ is ruled out by presented EPR measurements.

The distribution of XANES signal intensity over the pre-edge region depends on the splitting of the spin-allowed electron final states and comprises several components which correspond to transition to different crystal field-induced levels. The actual number of components depends on both the Fe oxidation state and its NN-coordination geometry [56-61]. The ground state of $\mathrm{Fe}^{2+}$ free ion is the ${ }^{5} \mathrm{D}$ multiplet with the orbital momentum $\mathrm{L}=2$, the spin $\mathrm{S}=2$ and degeneracy $(2 \mathrm{~L}+1)(2 \mathrm{~S}+1)=25$. The electronic structure of the $\mathrm{Fe}^{2+}$ ion incorporated into CdTe crystal results from multiple splitting of this highly degenerate ground state [58]. Orbital degeneracy is lifted due to the presence of Ch ligands, and in a highly symmetric tetrahedral crystal field the 25 -fold degenerate high spin term ${ }^{5} \mathrm{D}$ splits into orbital doublet ${ }^{5} \mathrm{E}$ $\left(\mathrm{e}_{\mathrm{g}}\right)$ and orbital triplet ${ }^{5} \mathrm{~T}_{2}\left(\mathrm{t}_{2 \mathrm{~g}}\right)$ separated by the crystal field parameter $(\Delta)$, as shown in Fig. 6. The crystal field states are further split by the second order spin-orbit interaction: the lower term ${ }^{5} \mathrm{E}$ splits into five, and the higher ${ }^{5} \mathrm{~T}_{2}$ term into six levels (see Fig. 6.) [58]. For Fe ${ }^{2+}$ in 
$\mathrm{CdTe}, \Delta=0.307 \mathrm{eV}[62]$, so that at RT only the ${ }^{5} \mathrm{E}-$ derived states are populated. Beyond spinorbit coupling, distortion of the tetrahedral crystal field (presence of different anions in the present case) also leads to symmetry reduction and $t_{2 \mathrm{~g}}$ states split into $\mathrm{e}_{\mathrm{g}}$ and $\mathrm{a}_{1 \mathrm{~g}}$ levels. The $4 p$ orbitals transform as $t_{2}$, so they will only mix with the $3 \mathrm{~d} \mathrm{t}_{2}$ orbitals. The SO interaction does not couple states belonging to different irreducible representations, but induces mixing between $\mathrm{E}$ and $\mathrm{T}_{2}$ terms [63]. The $\mathrm{t}_{2 \mathrm{~g}}$-derived $\mathrm{e}_{\mathrm{g}}$ states then mix with the original $\mathrm{e}_{\mathrm{g}}$ ones, and form two new doublets $\mathrm{e}_{(1) \mathrm{g}}$ and $\mathrm{e}_{(2) \mathrm{g}}$. The degree of mixing increases as the trigonal distortion increases and $\mathrm{Fe}$ d-derived $\mathrm{e}_{\mathrm{g}}$ states will further hybridize with the $\mathrm{Ch} \mathrm{p}$-states. Excitation of 1s electron to either $t_{2 g}$, or $e_{g}$ orbital gives two possible valence electron configurations, ${ }^{5} \mathrm{~T}_{2 \mathrm{~g}}$ and ${ }^{5} E_{g}$. Consequently, two pre-edge features are expected, with the first feature containing transitions into the ${ }^{4} \mathrm{~A}_{2},{ }^{4} \mathrm{~T}_{2}$, and ${ }^{4} \mathrm{~T}_{1}$ states and the second feature containing the transition into the higher energy ${ }^{4} \mathrm{~T}_{1}$ state [62-64].

To fit the pre-edge region of the experimental XANES spectra, two Lorentzian functions were used (as indicated by the shoulder in the second derivative of the data-see Fig. 5a inset). The baseline, approximated by an arctangent function, has been subtracted prior to fitting. The peak separation (7112 and $7113 \mathrm{eV}$ in CdFeTe(Se); 7111.5 and $7113 \mathrm{eV}$ in CdFeTeS, see Fig. 5) is a direct probe of the ligand-field strength, which is mainly determined by the nature of the ligands and metal ligand distance (inversely proportional to the fifth power of the metal-ligand bond length). Thus smaller $\mathrm{S}$ ion which can get closer to Fe results in a much stronger field.

\subsection{Fe $L_{2,3}$-edge XANES spectra}

To extract more detailed information on Fe-coordination structure and evolution of pdhybridization, XANES spectra were also recorded at $\mathrm{Fe}_{2,3}$-edge, which directly probes 
unoccupied Fe $3 d$ states (predominantly $2 p \rightarrow 3 d$ dipole transitions). The $\mathrm{Fe}_{2,3}$ XANES spectra are especially sensitive to local chemical environment, charge state, local crystal fields and $\mathrm{Fe}-3 \mathrm{~d} / \mathrm{Ch}-\mathrm{p}$ orbital mixing $[64,65]$. Normalized $\mathrm{Fe} \mathrm{L}_{2,3}-$ edge XANES spectra of $\mathrm{CdFeTeSe}(\mathrm{S})$ samples taken at $80 \mathrm{~K}$ are presented in Fig. 7. Due to spin-orbit splitting of the $2 p$ core holes $\left(2 p_{1 / 2}\right.$ and $\left.2 p_{3 / 2}\right)$, the $L_{3}$ and $L_{2}$ absorption lines are separated by as much as 13 $14 \mathrm{eV}$. As compared to CdFeTeSe spectrum (see Fig. 7a), peculiar shape of the CdFeTeS spectrum (see Fig. 7b) reflects subtitle differences in $\mathrm{Fe}-3 \mathrm{~d} / \mathrm{Te}(\mathrm{S})-\mathrm{p}$ hybridization. Also, larger $\mathrm{L}_{2,3}$ line splitting in $\mathrm{CdFeTeS}$ is due to stronger crystal-field effect in this sample, as already indicated by the pre-edge shape of its K-edge XANES spectra (see Fig. 5c). However, when the XANES spectra recorded in external magnetic field with right and left circularly polarized X-rays are subtracted (not shown), no signal remains beyond the noise. The absence of the XMCD signal implies that, similarly to $\mathrm{CdFeTe}(\mathrm{Se})$, the $\mathrm{Fe}^{2+}$ ground state remains magnetically inactive also in CdFeTeS sample.

\subsection{Results of calculations}

Standard GGA parameterization of Perdew, Burke and Ernzerhoff [35] overestimates CdTe unit cell parameter $\left(\mathrm{a}_{\mathrm{GGA}}=6.62 \AA\right)$. Good agreement with the experimental value $\left(\mathrm{a}_{\mathrm{exp}}=6.48 \AA\right.$ [49]) is achieved when WC parameterization is used ( $\mathrm{a}_{\mathrm{wC}}=6.49 \AA$ ). However, the calculated value of the energy gap $\left(E_{g}\right)$ is still greatly underestimated $\left(E_{g}{ }^{\text {calc. }}=0.44 \mathrm{eV}\right.$ as compared to $\mathrm{E}_{\mathrm{g}}{ }^{\mathrm{exp}}=1.5 \mathrm{eV}$ at $300 \mathrm{~K}$ [49]). The $\mathrm{NN}$ distances obtained from the geometry relaxation calculations $\left(2.62 \AA\right.$ in $\mathrm{Cd}_{3} \mathrm{FeTe}_{4} ; 2.61 \AA$ in $\left.\mathrm{Cd}_{31} \mathrm{FeTe}_{32}\right)$ are in good agreement with both

EXAFS (see Table 1) and experimentally determined Fe-Te distance (2.67 $\AA$ [49]). Note that agreement is achieved only after SP treatment had been included. Selected results of the electronic structure calculations with SO effects included are presented in Fig. 8. More details 
can be found in Supplementary material. Spin-up and spin-down states are shown above and below $\mathrm{x}$-axis respectively, with vertical line denoting Fermi level $\left(\mathrm{E}_{\mathrm{F}}\right)$ at $0 \mathrm{eV}$. The $\mathrm{SO}$ coupling lifts degeneracy of some states (in particular $\mathrm{Cd} 4 \mathrm{~d}$-states), but at the same time it leads to further reduction of already underestimated band gap (see Supplementary material for more details).

Total and atomic Fe densities of states (DOS) of previously optimized $\mathrm{Cd}_{3} \mathrm{FeTe}_{4}$ structure are shown in Fig. 8a. There is a large exchange splitting between majority spin-up states and minority spin-down states around $\mathrm{E}_{\mathrm{F}}$ and the spin-up gap is much larger than the spin-down gap. Spin-up Fe 3d-states are almost completely diffused into the VB close to its bottom (this region is dominated by Te $\mathrm{p}$ and to some extent $\mathrm{Cd} \mathrm{p}$ states- see Supplementary material for more details). Spin-down Fe 3d-states are localized in the vicinity of $\mathrm{E}_{\mathrm{g}}$ (close to the VB top and CB bottom). Spin-orbit interaction pulls down occupied Fe 3d spin down-states into VB and pushes empty Fe 3d spin-down states higher into CB (see Supplementary material for more details). The most prominent feature of the spin-down Fe 3d partial DOS is splitting of $e_{g}$ states at $E_{F}$ (see Fig. 8b) which causes the DOS at $E_{F}$ to vanish, thus essentially changing the nature of $\mathrm{Cd}_{3} \mathrm{FeTe}_{4}$ system from "half metallic" to insulating. A true gap opens with zero DOS at $\mathrm{E}_{\mathrm{F}}$ and thus $\mathrm{Cd}_{3} \mathrm{FeTe}_{4}$ is predicted to be an intrinsic insulator.

In $\mathrm{Cd}_{31} \mathrm{FeTe}_{32}$ system, Fe spin-down states are pushed out of both $\mathrm{VB}$ and $\mathrm{CB}$, which results in nearly symmetrical shape of the spin-dependent VB and CB. In spite of that, both the spin-up gap and the spin-down gap remain nearly constant with Fe concentration (see Fig. 8c). Due to lower Fe concentration (with more localized nature of states and less prominent mixing with SO-split states of surrounding host atoms), Fe 3d-states preserve much of their atomic-like character. The spin-up Fe 3d-states have only one narrow peak deep inside VB 
(around $-3 \mathrm{eV}$, see Fig. 8c). Spin-down states are localized inside the band gap with considerable DOS at $\mathrm{E}_{\mathrm{F}}$ (see Fig. 8d). The fact that only one spin channel contributes to the DOS at $E_{F}$ makes these materials suitable for spin selective electronic transport applications.

\subsection{Charge density analysis}

The results of Bader's charge density analysis of $\mathrm{Cd}_{3} \mathrm{FeTe}_{4}$ are summarized in Tables 2 and 3 . Iron spin-up atomic basin is larger and much more populated than the spin-down atomic basin. Tellurium and Cd spin-down states are more spatially delocalized, but slightly less populated than the spin-up states. Iron and $\mathrm{Cd}$ atoms are essentially electron donors and $\mathrm{Te}$ is electron acceptor (see Table 2). Excess charge on Fe (0.618 e) is slightly larger than the excess charge on $\mathrm{Cd}(0.489 \mathrm{e})$. Local magnetic moment on $\mathrm{Fe}\left(3.837 \mu_{\mathrm{B}}\right)$, calculated using charge integration over attractor basins, is highly localized and induces extremely small spinpolarization on neighboring Te and $\mathrm{Cd}$ atoms (see Table 2). The VB carriers (having mainly Te p-character) interact anti-ferromagnetically with Fe spins, since the spin magnetic moments on Fe and Te atoms are antiparallel.

The Fe-Te and Cd-Te bond critical points (bcp's) have been identified for total, spin-up and spin-down charge density scalar fields. The charge density values in Fe-Te bcp $(\rho=5.666$ $\left.\cdot 10^{-1} \mathrm{e} / \AA^{3}\right)$ and Cd-Te bcp $\left(\rho=4.968 \cdot 10^{-1} \mathrm{e} / \AA^{3}\right)$ are comparable (see Table 3$)$. The same goes for the values of charge density Laplacian (measure of the local charge concentration/depletion), with positive values in favor of closed-shell interactions. The FeTe bcp's of the spin-up and spin-down charges are slightly displaced from each other and generate a small magnetic dipole at the bcp. This is the exact electron charge distribution portrait of the exchange interaction in DMS systems with tetrahedral local structures around 3d-TM ion, established in one of our previous works [13]. 


\section{Conclusion}

Detailed studies of local and electronic structure around $\mathrm{Fe}$ in $\mathrm{Cd}_{0.97} \mathrm{Fe}_{0.03} \mathrm{Te}$, $\mathrm{Cd}_{0.98} \mathrm{Fe}_{0.02} \mathrm{Te}_{0.97} \mathrm{Se}_{0.03}$ and $\mathrm{Cd}_{0.99} \mathrm{Fe}_{0.01} \mathrm{Te}_{0.91} \mathrm{~S}_{0.09}$ multinary chalcogenides by means of $\mathrm{X}$-ray absorption fine structure (XAFS), X-ray magnetic circular dichroism (XMCD), electron paramagnetic resonance (EPR) and first principles calculations, revealed that $\mathrm{Fe}$ incorporation into CdTe lattice primarily affects the arrangement of atoms in its immediate surrounding. Local and electronic structures around $\mathrm{Fe}$ in $\mathrm{Cd}_{0.97} \mathrm{Fe}_{0.03} \mathrm{Te}$ and $\mathrm{Cd}_{0.98} \mathrm{Fe}_{0.02} \mathrm{Te}_{0.97} \mathrm{Se}_{0.03}$ have been found to exhibit similar characteristics, and the first coordination sphere around Fe comprises four Te atoms located at approximately the same distance. In $\mathrm{Cd}_{0.99} \mathrm{Fe}_{0.01} \mathrm{Te}_{0.91} \mathrm{~S}_{0.09}$, however, local bimodal distribution of nearest neighbour distances has been revealed: one $\mathrm{Fe}-\mathrm{Te}$ bond is replaced with much shorter $\mathrm{Fe}-\mathrm{S}$ bond, which results in much stronger crystal-field. Besides, due to presence of S tetrahedral symmetry at the $\mathrm{Fe}^{2+}$ site is broken, which affects the distribution of its energy levels. However, absence of the XMCD signal implies that, similarly to $\mathrm{Cd}_{0.97} \mathrm{Fe}_{0.03} \mathrm{Te}$ and $\mathrm{Cd}_{0.98} \mathrm{Fe}_{0.02} \mathrm{Te}_{0.97} \mathrm{Se}_{0.03}$, the $\mathrm{Fe}^{2+}$ ground state remains magnetically inactive also in $\mathrm{Cd}_{0.99} \mathrm{Fe}_{0.01} \mathrm{Te}_{0.91} \mathrm{~S}_{0.09}$. First principles calculations of $\mathrm{Cd}_{3} \mathrm{FeTe}_{4}$ and $\mathrm{Cd}_{31} \mathrm{FeTe}_{32}$ systems were carried out to reveal electronic consequences of $\mathrm{Fe}$ incorporation into $\mathrm{CdTe}$ semiconductor host. Special attention is paid to the treatment of exchange-correlation interaction and the description of highly localized Fe 3d-states. Good agreement with experimentally determined $\mathrm{Fe}-\mathrm{Te}$ distance is achieved by using $\mathrm{Wu}$ and Cohen parameterization, but only after inclusion of SP treatment. It has been found that large exchange splitting between majority spin-up states and minority spin-down states around $\mathrm{E}_{\mathrm{F}}$ exists in both $\mathrm{Cd}_{3} \mathrm{FeTe}_{4}(25$ at. $\% \mathrm{Fe})$ and $\mathrm{Cd}_{31} \mathrm{FeTe}_{32}(3.125$ at.\% $\mathrm{Fe}$ ) model systems. The spin-up gap is much larger than the spindown gap, but they both remain nearly constant with Fe concentration. Spin-orbit interaction 
pulls down occupied Fe 3d spin-down states into valence band and pushes empty Fe 3d spindown states higher into CB. However, while in $\mathrm{Cd}_{3} \mathrm{FeTe}_{4}$ DOS at Fermi level completely vanishes (thus essentially changing the nature of $\mathrm{Cd}_{3} \mathrm{FeTe}_{4}$ system from "half metallic" to insulating), in $\mathrm{Cd}_{31} \mathrm{FeTe}_{32}$ considerable DOS is still present at the Fermi level. The fact that only one spin channel contributes to the DOS at the Fermi level, makes these materials suitable for spin selective electronic transport applications.

\section{Acknowledgements}

The research leading to these results has received funding from the European Community's Seventh Framework Programme (FP7/2007-2013) under the Grant agreement N 226716 and is supported by Serbian Ministry of Science and Technological Development under the Grant III 45003. The authors gratefully acknowledge DESY and Elettra for providing the beamtime for XAFS experiments.

\section{References}

[1] J.K. Furdyna, Diluted magnetic semiconductors, J. Appl. Phys. 64 (1988) R29-R63.

[2] S.J. Pearton, C.R. Abernathy, D.P. Norton, A.F. Hebard, Y.D. Park, L.A. Boatner, J.D. Budai, Advances in wide bandgap materials for semiconductor spintronics, Mat. Sci. Eng. R. 40 (2003) 137-168.

[3] T. Dietl, A ten-year perspective on dilute magnetic semiconductors and oxides, Nat. Mater. 9 (2010) 965-974. 
[4] D.D. Awschalom, M.E. Flatté, Challenges for semiconductor spintronics, Nat. Phys. 3 (2007) 153-159.

[5] A. Fert, Nobel Lecture: Origin, development, and future of spintronics, Rev. Mod. Phys. 80 (2008) 1517-1530.

[6] I. Radisavljević, N. Novaković, B. Matović, N. Paunović, M. Medić, N. Bundaleski, V. Andrić, O.M.N.D. Teodoro, Comprehensive studies of structural, electronic and magnetic properties of $\mathrm{Zn}_{0.95} \mathrm{Co}_{0.05} \mathrm{O}$ nanopowders, Mater. Res. Bull. 74 (2016) 78-84.

[7] A. Bonanni, A. Navarro-Quezada, T. Li, M. Wegscheider, Z. Matej, V. Holy, R. T. Lechner, G. Bauer, M. Rovezzi, F. D’Acapito, M. Kiecana, M. Sawicki, T. Dietl, Controlled aggregation of magnetic ions in a semiconductor: an experimental demonstration, Phys. Rev. Lett. 101 (2008) 135502-13.

[8] L.M.C. Pereira, J.P. Araújo, U. Wahl, S. Decoster, M.J. Van Bael, K. Temst, A. Vantomme, Searching for room temperature ferromagnetism in transition metal implanted ZnO and GaN, J. Appl. Phys. 113 (2013) 023903-9.

[9] R. P. Panguluri, P. Kharel, C. Sudakar, R. Naik, R. Suryanarayanan, V. M. Naik, A. G. Petukhov, B. Nadgorny, G. Lawes, Ferromagnetism and spin-polarized charge carriers in $\mathrm{In}_{2} \mathrm{O}_{3}$ thin films, Phys. Rev. B 79 (2009) 165208-6.

[10] J. M. D. Coey, P. Stamenov, R. D. Gunning, M. Venkatesan, K. Paul, Ferromagnetism in defect-ridden oxides and related materials, New J. Phys. 12 (2010) 053025-14.

[11] S.J. Pearton, M.E. Overberg, G.T. Thaler, C.R. Abernathy, J. Kim, F. Ren, N. Theodoropoulou, A.F. Hebard, Y. D. Park, Room temperature ferromagnetism in GaMnN and GaMnP, Phys. Status Solidi A 195 (2003) 222-227. 
[12] H. Subramanian, J.E. Han, In-plane uniaxial magnetic anisotropy in (Ga, Mn)As due to local lattice distortions around $\mathrm{Mn}^{2+}$ ions, J. Phys. Condens. Matter 25 (2013) 20600512.

[13] I. Radisavljević, N. Novaković, N. Romčević, M. Mitrić, B. Kuzmanović, S. Bojanić, N. Ivanović, Electronic aspects of formation and properties of local structures around $\mathrm{Mn}$ in $\mathrm{Cd}_{1-\mathrm{x}} \mathrm{Mn}_{\mathrm{x}} \mathrm{Te}_{1-\mathrm{y}} \mathrm{Se}_{\mathrm{y}}$, Mat. Chem. Phys. 167 (2015) 236-245.

[14] H.J.M. Swagten, C.E.P. Gerrits, A. Twardowski, W.J.M. de Jonge, Magnetization steps in iron-based diluted magnetic semiconductors, Phys. Rev. B 41 (1990) 7330-7333.

[15] A. Mycielski, M. Arciszewska, W. Dobrowolski, C. Rigaux, A. Mauger, C. Testelin, C. Julien, A. Lenard, M. Guillot, B. Witkowska, M. Menant, II-VI Semiconductors Doped with Transition Metals Other Than Mn, Phys. Scr. T39 (1991) 119-123.

[16] M. Kobayashi, Y. Ishida, J.I. Hwang, G.S. Song, A. Fujimori, C.S. Yang, L. Lee, H.J. Lin, D.J. Huang, C.T. Chen, Y. Takeda, K. Terai, S.I. Fujimori, T. Okane, Y. Saitoh, H. Yamagami, K. Kobayashi, A. Tanaka, H. Saito, K. Ando, Local electronic structure of $\mathrm{Cr}$ in the II-VI diluted ferromagnetic semiconductor $\mathrm{Zn}_{1-\mathrm{x}} \mathrm{Cr}_{\mathrm{x}} \mathrm{Te}$, New J. Phys. 10 (2008) $055011-15$.

[17] I. Radisavljević, N. Ivanović, N. Novaković, N. Romčević, M. Mitrić, V. Andrić, H.-E. Mahnke, Local structures in $\mathrm{Pb}_{1-\mathrm{x}} \mathrm{Mn}_{\mathrm{x}}$ Te systems, X-Ray Spectrom. 36 (2007) 150-157.

[18] I. Radisavljević, N. Novaković, N. Ivanović, N. Romčević, M. Manasijević, M. H.-E. Mahnke, XAFS studies of nickel-doped lead telluride, Physica B 404 (2009) 50325034. 
[19] N. Theodoropoulou, A. F. Hebard, S.N.G. Chu, M.E. Overberg, C.R. Abernathy, S.J. Pearton, R.G. Wilson, J. M. Zavada, Characterization of high dose Fe implantation into p-GaN, Appl. Phys. Lett. 79 (2001) 3452-3454.

[20] H. Przybylinska, A. Bonanni, A. Wolos, M. Kiecana, M. Sawicki, T. Dietl, H. Malissa, C. Simbrunner, M. Wegscheider, H. Sitter, K. Rumpf, P. Granitzer, H. Krenn, W. Jantsch, Magnetic properties of a new spintronic material-GaN:Fe, Mater. Sci. Eng. B $126(2006) 222-225$.

[21] S.B. Singh, M.V. Limaye, S K. Date, S. Gokhale, S.K. Kulkarni, Iron substitution in CdSe nanoparticles: Magnetic and optical properties, Phys. Rev. B 80 (2009) 235421-8.

[22] K. Kaur, G. S. Lotey, N.K. Verma, Optical and magnetic properties of Fe-doped CdS dilute magnetic semiconducting nanorods, J. Mater. Sci.: Mater. Electron. 25 (2014) $2605-2610$.

[23] S.K. Mohanta, S.N. Mishra, Lattice location and local magnetism of recoil implanted Fe impurities in wide and narrow band semiconductors CdTe, CdSe, and InSb: Experiment and theory, J. Appl. Phys. 115 (2014) 173908-6.

[24] X. Lu, I. Miotkowski, A. K. Ramdas, S. Rodriguez, H. Alawadhi, T. M. Pekarek, Raman scattering in the diluted magnetic semiconductor $\mathrm{Zn}_{1_{-} \mathrm{x}} \mathrm{Fe}_{\mathrm{x}} \mathrm{Te}$ : A van Vleck paramagnet, Phys Rev. B 76 (2007) 035208-9.

[25] I. Radisavljević, J. Trigueiro, N. Bundaleski, M. Medić, N. Romčević, O.M.N.D. Teodoro, M. Mitrić, N. Ivanović, XAFS and XPS analysis of $\mathrm{Zn}_{0.98} \mathrm{Fe}_{0.02} \mathrm{Te}_{0.91} \mathrm{Se}_{0.09}$ semiconductor, J. Alloys Compd. 632 (2015) 17-22. 
[26] B. Pukowska, J. Jaglarz, B. Such, T. Wagner, A. Kisiel, A. Mycielski, Optical investigations of the CdTeSe and CdMeTeSe (Me=Mn, Fe) semiconductors, J. Alloys Compd. 335 (2002) 35-42.

[27] I. Bozovic, C. Ahn, A new frontier for superconductivity, Nat. Phys. 10 (2014) 892-895.

[28] R. Hu, E.S. Bozin, J.B. Warren, C. Petrovic, Superconductivity, magnetism, and stoichiometry of single crystals of $\mathrm{Fe}_{1+\mathrm{y}}\left(\mathrm{Te}_{1-\mathrm{x}} \mathrm{S}_{\mathrm{x}}\right)_{z}$, Phys. Rev. B80 (2009) 2-8.

[29] G. Adhikary, D. Biswas, N. Sahadev, S. Ram, V. Kanchana, C.S. Yadav, P.L. Paulose, K. Maiti, Importance of ligands in the electronic properties of $\mathrm{FeTe}_{0.6} \mathrm{Se}_{0.4}, \mathrm{~J}$. Appl. Phys. 114 (2013) 163906-5.

[30] A. Winter, H. Pascher, H. Krenn, I. Miotkowski, A. K. Ramdas, Coherent stokes Raman spectroscopy of conduction electron spin flip transitions in $\mathrm{Cd}_{1-\mathrm{x}} \mathrm{Fe}_{\mathrm{x}} \mathrm{Te}$ : A Van Vleck paramagnet, Phys. Rev. B 78 (2008) 045213-4.

[31] A. Balzarotti, N. Motta, A. Kisiel, M. Zimnal-Starnawska, M.T. Czyźyk, Model of the local structure of random ternary alloys: Experiment versus theory, Phys. Rev. B 31 (1985) 7526-7539.

[32] S.M. Islam, B.A. Bunker, Studies of atomic correlations in quaternary semiconductor alloys using the extended X-ray absorption fine structure technique, Phys. Lett. A 156 (1991) 247-252.

[33] B. Belhadji, L. Bergqvist, R. Zeller, P.H. Dederichs, K. Sato, H. Katayama-Yoshida, Trends of exchange interactions in dilute magnetic semiconductors, J. Phys.: Condens. Matter 19 (2007) 436227-12. 
[34] N. Bundaleski, I. Radisavljević, J. Trigueiro, A.Tolstogouzov, Z. Rakočević, M. Medić, O.M.N.D.Teodoro, N. Romčević, N. Ivanović, Surface composition of $\mathrm{Cd}_{1-}$ ${ }_{x} \mathrm{Fe}(\mathrm{Mn})_{\mathrm{x}} \mathrm{Te}_{1-\mathrm{y}} \mathrm{Se}_{\mathrm{y}}$ systems exposed to air, Mat. Chem. Phys. 189 (2017) 35-43.

[35] N. Bundaleski, I. Radisavljević, N. Ivanović, Z. Rakočević, M. Medić Ilić, N. Romčević, O.M.N.D. Teodoro, Local, electronic and surface structure of multi-component $\mathrm{Fe}-$ doped CdTe(S) systems, Surf. Sci. 681 (2019) 76-86.

[36] B. Ravel, M. Newville, ATHENA, ARTEMIS, HEPHAESTUS: data analysis for X-ray absorption spectroscopy using IFEFFIT, J. Synchrotron Rad. 12 (2005) 537-541.

[37] I. Radisavljević, N. Ivanović, N. Novaković, N. Romčević, M. Mitrić, V. Andrić, H.-E. Mahnke, Structural aspects of changes induced in PbTe by doping with $\mathrm{Mn}$, In and Ga, J. Mater. Sci. 48 (2013) 8084-8100.

[38] P. Blaha, K. Schwarz, J. Luitz, WIEN 2k, Vienna University of Technology, Vienna, 1997. Improved and updated UNIX version of the original copyrighted WIEN code, published by P. Blaha, K. Schwarz, P. Sorantin, S.B. Trickey, Full-potential, linearized augmented plane wave programs for crystalline systems, Comput. Phys. Commun. 59 (1990) 399-415.

[39] J.P. Perdew, K. Burke, M. Ernzerhoff, Generalized Gradient Approximation Made Simple, Phys. Rev. Lett. 77 (1996) 3865-3868.

[40] Z. Wu, R. E. Cohen, More accurate generalized gradient approximation for solids, Phys. Rev. B 73 (2006) 235116-6.

[41] L.J. Sham, M. Schluter, Density-Functional Theory of the Energy Gap, Phys. Rev. Lett. $51(1983) 1888-1891$. 
[42] E. Guziewicz, B.J. Kowalski, K. Szamota-Sadowska, B.A. Orlowski, J. Mašek, R.L. Johnson, The influence of the Fe $3 \mathrm{~d}$ states on the electronic band structure of $\mathrm{CdTe} / \mathrm{Fe}$ and bulk $\mathrm{Cd}_{0.985} \mathrm{Fe}_{0.015}$ Te crystal, J. Alloys Compd. 286 (1999) 137-142.

[43] P.Y. Yu, M. Cardona, Fundamentals of Semiconductors: Physics and Materials Properties, $2^{\text {nd }}$ Edition, Springer-Verlag, 1999, p. 441.

[44] Á. Morales-García, R. Valero, Francesc Illas, An Empirical, yet Practical Way To Predict the Band Gap in Solids by Using Density Functional Band Structure Calculations, J. Phys. Chem. C 121 (2017) 18862-18866.

[45] J. Pan, W. K. Metzger, S. Lany, Spin-orbit coupling effects on predicting defect properties with hybrid functionals: A case study in CdTe, Phys. Rev. B 98 (2018) 054108-9.

[46] R. Bader, Atoms in Molecules: A Quantum Theory, Oxford University Press, USA, 1994.

[47] A. Otero-de-la-Roza, M.A. Blanco, A. Martín Pendás, V. Luaña, Critic: a new program for the topological analysis of solid-state electron densities, Comput. Phys. Commun. 180 (2009) 157-166.

[48] N.E. Brese, M. O’Keeffe, Bond-Valence Parameters for Solids, Acta Cryst. B 47 (1991) $192-197$.

[49] W. M. Haynes CRC handbook of chemistry and physics: a ready-reference book of chemical and physical data. Boca Raton, CRC Press, 2009.

[50] J.A. Van Vechten, J. C. Phillips, New Set of Tetrahedral Covalent Radii, Phys. Rev. B 2 (1970) 2160-2167. 
[51] P. Pyykkö, Refitted tetrahedral covalent radii for solids, Phys. Rev. B 85 (2012) 0241157.

[52] A. Iadecola, B. Joseph, A Puri, L. Simonelli, Y. Mizuguchi, D. Testemale, O. Proux, J.L. Hazemann, Y. Takano, N.L. Saini, Random alloy-like local structure of Fe(Se, S) $)_{1-}$ ${ }_{\mathrm{x}} \mathrm{Te}_{\mathrm{x}}$ superconductors revealed by extended $\mathrm{x}$-ray absorption fine structure, J. Phys. Condens. Matter 23 (2011) 425701-7.

[53] Y. Ishida, M. Kobayashi, J.-I. Hwang, Y. Takeda, S. Fujimori, T. Okane, K. Terai, Y. Saitoh, Y. Muramatsu, A. Fujimori, A. Tanaka, H. Saito, K. Ando, X-ray Magnetic Circular Dichroism and Photoemission Study of the Diluted Ferromagnetic Semiconductor $\mathrm{Zn}_{1-\mathrm{x}} \mathrm{Cr}_{\mathrm{x}} \mathrm{Te}$, Appl. Phys. Express 1 (2008) 041301-3.

[54] B. Joseph, A. Iadecola, L. Simonelli, Y. Mizuguchi, Y. Takano, T. Mizokawa, N.L. Saini, A study of the electronic structure of $\mathrm{FeSe}_{1-\mathrm{x}} \mathrm{Te}_{\mathrm{x}}$ chalcogenides by $\mathrm{Fe}$ and $\mathrm{Se} \mathrm{K}-$ edge $\mathrm{x}$-ray absorption near edge structure measurements, J. Phys. Condens. Matter 22 (2010) 485702-5.

[55] J.M. Langer, H. Heinrich, Deep-level Impurities: A Possible Guide to Prediction of Band-Edge Discontinuities in Semiconductor Heterojunctions, Phys. Rev. Lett. 55 (1985) 1414-1417.

[56] N. Hollmann, M. Valldor, H. Wu, Z. Hu, N. Qureshi, T. Willers, Y.Y. Chin, J.C. Cezar, A. Tanaka, N.B. Brookes, L.H. Tjeng, Orbital occupation and magnetism of tetrahedrally coordinated iron in $\mathrm{CaBaFe}_{4} \mathrm{O}_{7}$, Phys. Rev. B 83 (2011) 180405(R)-4.

[57] E. Malguth, A. Hoffmann, M.R. Phillips, Fe in III-V and II-VI semiconductors, Phys. Status Solidi B 245 (2008) 455-480. 
[58] W. Low, M. Weger, Paramagnetic Resonance and Optical Spectra of Divalent Iron in Cubic Fields. I. Theory, Phys. Rev. 118 (1960) 1119-1130.

[59] I. Radisavljević, B. Kuzmanović, N. Novaković, H.-E. Mahnke, LJ. Vulićević, S. Kurko, N. Ivanović, Structural stability and local electronic properties of some EC synthesized magnetite nanopowders, J. Alloys Compd. 697 (2017) 409-416.

[60] T. Westre, P. Kennepohl, J. DeWitt, B. Hedman, K. Hodgson, E. Solomon, A Multiplet Analysis of Fe K-Edge 1s $\rightarrow$ 3d Pre-Edge Features of Iron Complexes, J. Am. Chem. Soc. 119 (1997) 6297-6314.

[61] T. Yamamoto, Assignment of pre-edge peaks in K-edge $\mathrm{X}$-ray absorption spectra of 3d transition metal compounds: electric dipole or quadrupole?, X-Ray Spectrom. 37 (2008) $572-584$.

[62] C. Testelin, C. Rigaux, A. Mycielski, M. Menant, Exchange interactions in CdFeTe semimagnetic semiconductors, Solid State Commun. 78 (1991) 659-663.

[63] C. Testelin, C. Rigaux, A. Mauger, A. Mycielski, Dynamic Jahn-Teller effect on the far-infrared spectrum of $\mathrm{Fe}^{2+}$ in $\mathrm{Cd}_{1-\mathrm{x}} \mathrm{Fe}_{\mathrm{x}} \mathrm{Te}$ compounds, Phys. Rev. B 46 (1992) $2183-$ 2192.

[64] C. Mitra, Z. Hu, P. Raychaudhuri, S. Wirth, S.I. Csiszar, H.H. Hsieh, H.-J. Lin, C.T. Chen, L.H. Tjeng, Direct observation of electron doping in $\mathrm{La}_{0.7} \mathrm{Ce}_{0.3} \mathrm{MnO}_{3}$ using $\mathrm{x}-$ ray absorption spectroscopy, Phys. Rev. B 67 (2003) 092404-5.

[65] L.A.J. Garvie, P.R. Buseck, Ratios of ferrous to ferric iron from nanometre-sized areas in minerals, Nature 396 (1998) 667-670. 


\section{Tables and Table captions}

Table 1. Interatomic distances $(r)$, Debye-Waller factors $\left(\sigma^{2}\right)$ and coordination numbers $(n)$ determined by the EXAFS data analysis of samples $\mathrm{Cd}_{0.97} \mathrm{Fe}_{0.03} \mathrm{Te}(\mathrm{CdFeTe})$,

$\mathrm{Cd}_{0.98} \mathrm{Fe}_{0.02} \mathrm{Te}_{0.97} \mathrm{Se}_{0.03}(\mathrm{CdFeTeSe})$ and $\mathrm{Cd}_{0.99} \mathrm{Fe}_{0.01} \mathrm{Te}_{0.91} \mathrm{~S}_{0.09}(\mathrm{CdFeTeS})$. Experimental uncertainties of the parameters evaluated in the fit are given in parenthesis. Fixed parameters are denoted by star. The passive electron reduction factor $\mathrm{S}_{0}{ }^{2}$ was set to 0.7 and the fit quality factor $\left(\mathrm{R}\right.$-factor) was better than $1.5 \%$. Bond valence is calculated as $v_{\mathrm{ij}}=\exp \left[\left(\mathrm{R}_{\mathrm{ij}}-\mathrm{r}\right) / \mathrm{b}\right][48]$, where $b$ is empirical constant $(0.37 \AA)$ and $R_{i j}$ bond valence parameter $\left(R_{\mathrm{Fe}-\mathrm{Te}}=2.53 \AA\right.$, $\mathrm{R}_{\mathrm{Fe}-}$ $\mathrm{s}=2.16 \AA$ ). Iron valence $\left(\mathrm{V}_{\mathrm{Fe}}\right)$ is calculated as a sum of $v_{\mathrm{ij}}$ assuming four $\mathrm{Fe}-\mathrm{Ch}$ bonds .

\begin{tabular}{|c|c|c|c|c|c|c|c|c|c|c|}
\hline \multirow{2}{*}{$\begin{array}{l}\text { Sample } \\
\text { Coord. }\end{array}$} & \multicolumn{3}{|c|}{$\mathrm{Cd}_{0.97} \mathrm{Fe}_{0.03} \mathrm{Te}$} & \multicolumn{3}{|c|}{$\mathrm{Cd}_{0.98} \mathrm{Fe}_{0.02} \mathrm{Te}_{0.97} \mathrm{Se}_{0.03}$} & \multicolumn{4}{|c|}{$\mathrm{Cd}_{0.99} \mathrm{Fe}_{0.01} \mathrm{Te}_{0.91} \mathrm{~S}_{0.09}$} \\
\hline & $\mathrm{Fe}-\mathrm{Te}_{\mathrm{I}}$ & $\mathrm{Fe}-\mathrm{Cd}_{\mathrm{II}}$ & $\mathrm{Fe}-\mathrm{Te}_{\mathrm{III}}$ & $\mathrm{Fe}-\mathrm{Te}_{\mathrm{I}}$ & $\mathrm{Fe}-\mathrm{Cd}_{\mathrm{II}}$ & $\mathrm{Fe}-\mathrm{Te}_{\mathrm{III}}$ & $\mathrm{Fe}-\mathrm{Te}_{\mathrm{I}-1}$ & $\mathrm{Fe}-\mathrm{S}_{\mathrm{I}-2}$ & $\mathrm{Fe}-\mathrm{Cd}_{\mathrm{II}-1}$ & $\mathrm{Fe}-\mathrm{Cd}_{\mathrm{II}-2}$ \\
\hline$r$ & \multirow{3}{*}{$2.673(4)$} & $4.56(4)$ & $5.32(2)$ & \multirow{3}{*}{$2.671(2)$} & \multirow{3}{*}{$4.55(3)$} & \multirow{3}{*}{$5.32(2)$} & \multirow{3}{*}{$2.684(7)$} & $2.37(2)$ & $4.10(9)$ & $4.80(10)$ \\
\hline 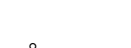 & & & & & & & & & & \\
\hline$(\AA)$ & & ${ }^{\#} 4.583$ & ${ }^{\#} 5.374$ & & & & & ${ }^{\#} 2.525$ & $\langle 4.51\rangle$ & \\
\hline$\sigma^{2}\left(\AA^{2}\right)$ & $0.0024(4)$ & $0.018(3)$ & $0.010(2)^{*}$ & $0.0021(2)$ & $0.016(2)$ & $0.016(3)$ & $0.0025(6)$ & 0.0025 & $0.018(6)$ & 0.018 \\
\hline$n$ & $4^{*}$ & $12^{*}$ & $12^{*}$ & $4^{*}$ & $12^{*}$ & $12^{*}$ & $3.1(2)$ & 0.9 & $5(3)$ & 7 \\
\hline$E_{0}(\mathrm{eV})$ & $0.3(3)$ & $0(1)$ & $0.3(3)$ & $1.6(2)$ & $0(1)$ & 1.6 & $0.3(9)$ & 0.3 & $4(3)$ & 4 \\
\hline$v_{i j}$ & 0.679 & - & - & 0.683 & - & - & 0.659 & 0.567 & - & - \\
\hline$V_{F e}$ & 2.716 & - & - & 2.732 & - & - & 2.544 & - & - & - \\
\hline
\end{tabular}

\footnotetext{
${ }^{\#}$ Distances in binary CdTe and CdS compounds [49].
} 
Table 2. Integrated properties of $\mathrm{Cd}_{3} \mathrm{FeTe}_{4}$ atomic basins obtained by electron charge density topology analysis (nn-nearest neighbour, nnn-next nearest neighbour).

\begin{tabular}{|c|c|c|c|c|c|c|}
\hline Atom & $\begin{array}{l}\mathrm{R}_{\mathrm{MT}} \\
(\AA)\end{array}$ & $\begin{array}{l}\text { Volume } \\
\left(\AA^{3}\right)\end{array}$ & & $\begin{array}{l}\text { Charge } \\
\text { (e) }\end{array}$ & $\begin{array}{l}\text { Excess } \\
\text { charge (e) }\end{array}$ & $\begin{array}{l}\text { Spin } \\
\text { moment }\left(\mu_{\mathrm{B}}\right)\end{array}$ \\
\hline \multirow[t]{3}{*}{$\mathrm{Fe}$} & 1.058 & Total & 18.314 & 25.382 & 0.618 & 3.837 \\
\hline & & up & 21.532 & 14.584 & & \\
\hline & & down & 15.926 & 10.747 & & \\
\hline \multirow[t]{3}{*}{ nnTe } & 1.217 & Total & 41.337 & 52.499 & -0.499 & -0.026 \\
\hline & & up & 40.660 & 26.267 & & \\
\hline & & down & 42.260 & 26.241 & & \\
\hline \multirow[t]{3}{*}{ nnnCd } & 1.217 & Total & 25.319 & 47.511 & 0.489 & 0.026 \\
\hline & & up & 25.150 & 23.768 & & \\
\hline & & down & 25.515 & 23.742 & & \\
\hline
\end{tabular}


Table 3. Properties of bond critical points (bcp's) in $\mathrm{Cd}_{3} \mathrm{FeTe}_{4}$ system: $\rho$-charge density; $\Delta \rho$-Laplacian of $\rho ; \mathrm{r}_{\mathrm{Te}(\mathrm{Fe})}-$ distance from $\mathrm{Te}(\mathrm{Fe})$ atom to the corresponding bcp; $|\mathrm{r}-\mathrm{d} / 2|-$ deviation of the bcp position from the half of the $\mathrm{Fe}(\mathrm{Cd})-\mathrm{Te}$ distance (d). Bond distance $\mathrm{d}_{\mathrm{Te}-\mathrm{Fe}}=2.629 \AA \mathrm{d}_{\mathrm{Te}-\mathrm{Cd}}=2.809 \AA$.

\begin{tabular}{|c|c|c|c|c|c|c|c|c|c|}
\hline Atoms & $\begin{array}{l}\mathrm{bcp} \\
\text { point }\end{array}$ & $\begin{array}{l}\text { Multi- } \\
\text { plicity }\end{array}$ & $\begin{array}{l}\text { Charge } \\
\text { type }\end{array}$ & $\begin{array}{l}\rho \cdot 10^{-1} \\
\left(\mathrm{e} / \AA^{3}\right)\end{array}$ & $\begin{array}{l}\Delta \rho \cdot 10^{-1} \\
\left(\mathrm{e} / \AA^{5}\right)\end{array}$ & $\begin{array}{l}\mathrm{r}_{\mathrm{Te}} \\
(\AA)\end{array}$ & $\begin{array}{l}\mathrm{r}_{\mathrm{Fe}} \\
(\AA)\end{array}$ & $\mathrm{r}_{\mathrm{Te}} / \mathrm{r}_{\mathrm{Fe}}$ & $\begin{array}{l}\mathrm{r}-\mathrm{d} / 2 \\
(\AA)\end{array}$ \\
\hline & group & & & & & & & & \\
\hline \multirow[t]{3}{*}{$\mathrm{Fe}-\mathrm{Te}$} & $\mathrm{C} 3 \mathrm{v}$ & 4 & Total & 5.666 & 5.154 & 1.482 & 1.147 & 1.292 & 0.168 \\
\hline & & & up & 2.946 & 3.856 & 1.423 & 1.206 & 1.180 & 0.108 \\
\hline & & & down & 2.563 & 4.194 & 1.571 & $1.058^{*}$ & 1.485 & 0.256 \\
\hline \multirow[t]{3}{*}{$\mathrm{Cd}-\mathrm{Te}$} & $\mathrm{Cs}$ & 12 & Total & 4.968 & 5.501 & 1.495 & 1.314 & 1.138 & 0.091 \\
\hline & & & up & 2.522 & 2.770 & 1.500 & 1.310 & 1.144 & 0.096 \\
\hline & & & down & 2.445 & 2.733 & 1.492 & 1.318 & 1.132 & 0.088 \\
\hline
\end{tabular}

*This bcp is at the very border between interstitial space and MT sphere. 


\section{Figure captions}

Fig. 1. X-ray diffractograms of samples (a) CdFeTeSe and (b) CdFeTeS.

Fig. 2. EPR spectra of samples (a) CdFeTe, CdFeTeSe and CdFeTeS and (b) sample CdFeTeS measured with and without UV lamp.

Fig. 3. Fe K-edge EXAFS spectra of samples (a) CdFeTe, (b) CdFeTeSe, (c) CdFeTeS, and (d-f) the corresponding FT transforms. Experimental data are represented with circles and the best fits with lines. Vertical lines denote fitting ranges.

Fig. 4. Fe K-edge XANES spectra of samples CdFeTe, CdFeTeSe and CdFeTeS.

Characteristic features appearing in the spectra are denoted by letters $a-e$.

Fig. 5. Pre-edge region of the Fe K-edge XANES spectra of samples (a) CdFeTe, (b)

CdFeTeSe and (c) CdFeTeS. Background (bkg), approximated with arctangent function had been subtracted prior to fitting with two Lorentzian functions (L1 and L2). Inset shows first and second derivative of the CdFeTe XANES spectrum, with the arrow pointing at the shoulder in the second derivative (see text for more details).

Fig. 6. A schematic diagram of the $\mathrm{Fe}^{2+}$ ion energy levels in cubic crystal field with tetrahedral symmetry (see text for more details).

Fig. 7. Fe $\mathrm{L}_{2,3}$-edge XANES spectra of samples (a) CdFeTeSe and (b) CdFeTeS.

Fig. 8. Total DOS of (a) $\mathrm{Cd}_{3} \mathrm{FeTe}_{4}$ and (b) $\mathrm{Cd}_{31} \mathrm{FeTe}_{32}$ systems with spin-orbit effects included. Spin-up and spin-down states are shown above and below $\mathrm{x}$-axis respectively, with vertical dashed line denoting Fermi level $\left(\mathrm{E}_{\mathrm{F}}\right)$ at $0 \mathrm{eV}$. Iron atomic DOS are presented with dotted line; (c) Crystal field-split Fe-3d states in valence band of $\mathrm{Cd}_{3} \mathrm{FeTe}_{4}$; (d) Details of $\mathrm{Cd}_{31} \mathrm{FeTe}_{32}$ DOS in the vicinity of $\mathrm{E}_{\mathrm{F}}$. 
Figure 1.

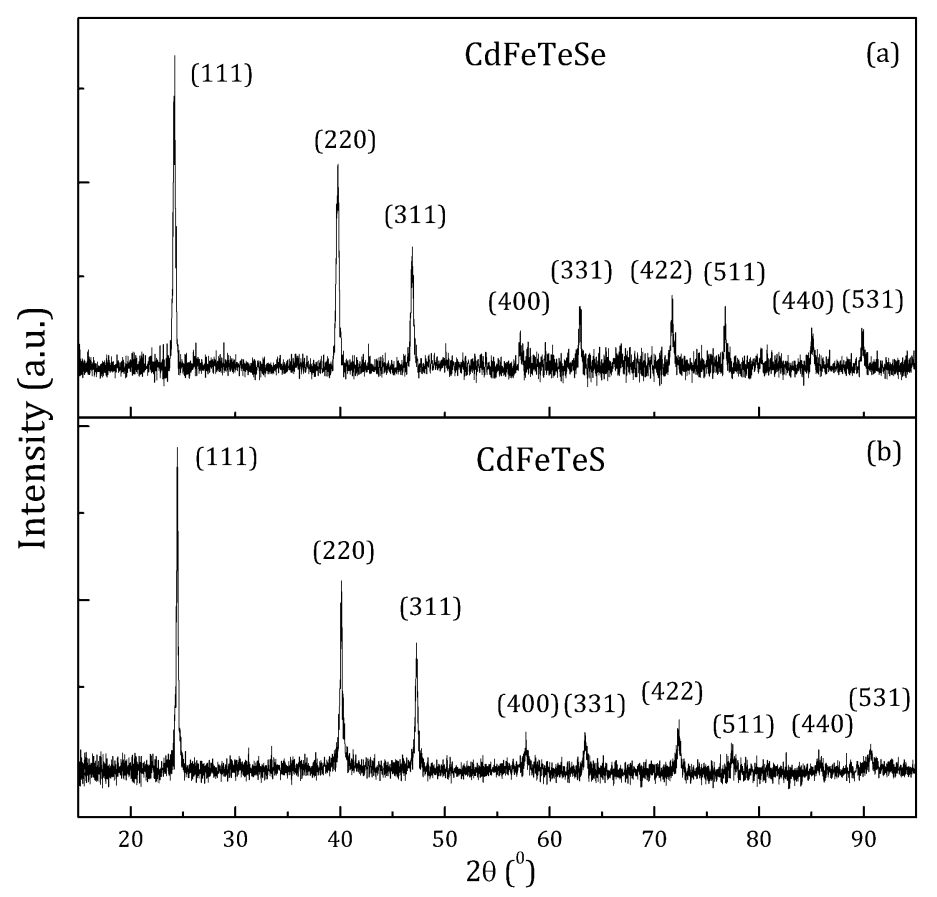

Figure 2.

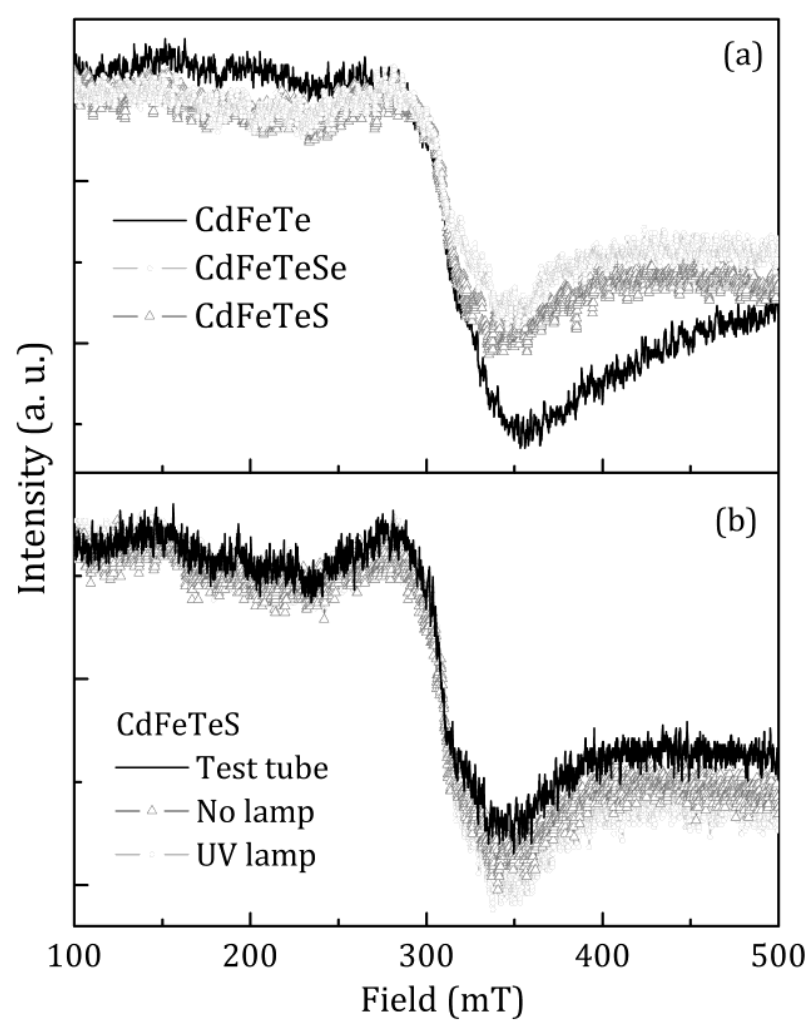


Figure 3.
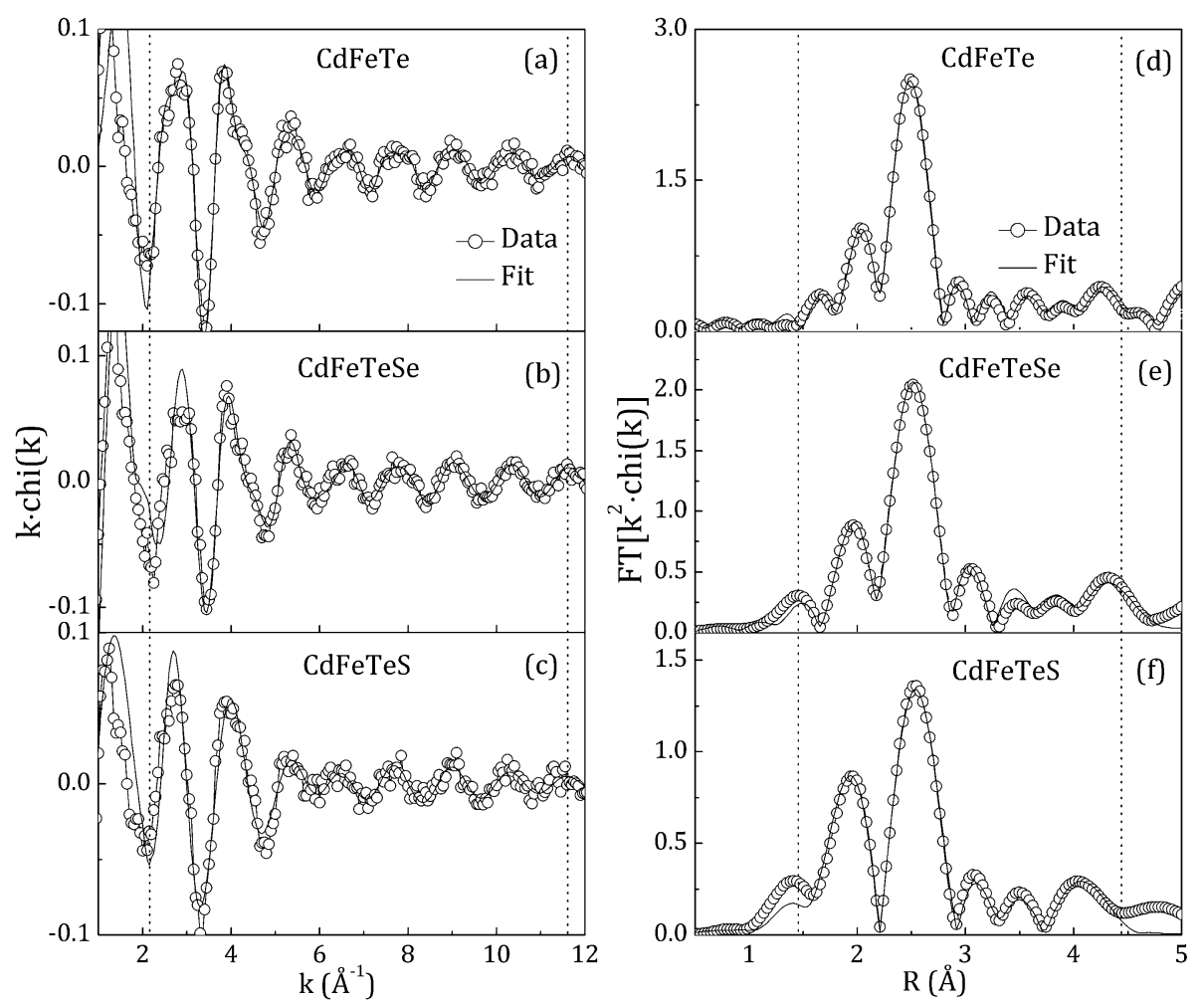

\section{Figure 4.}

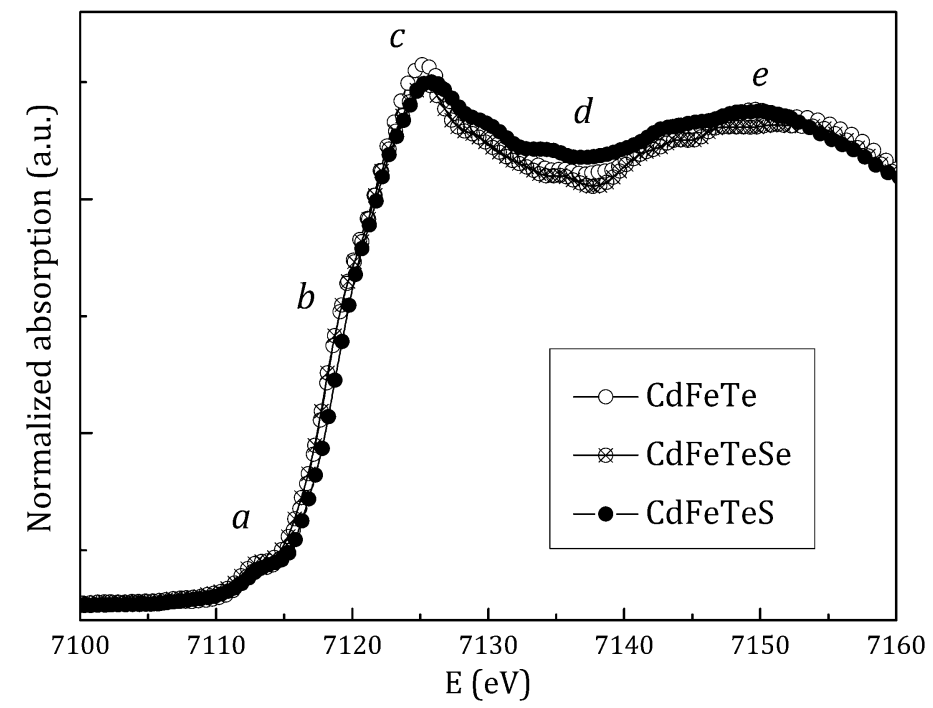


Figure 5.

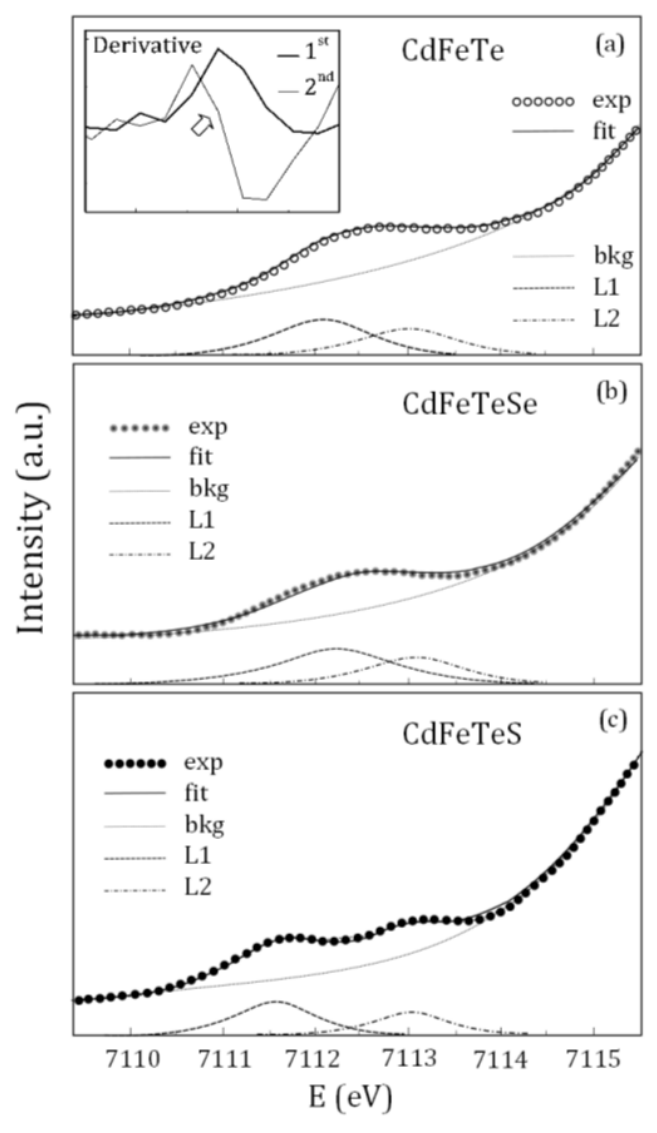

Figure 6.

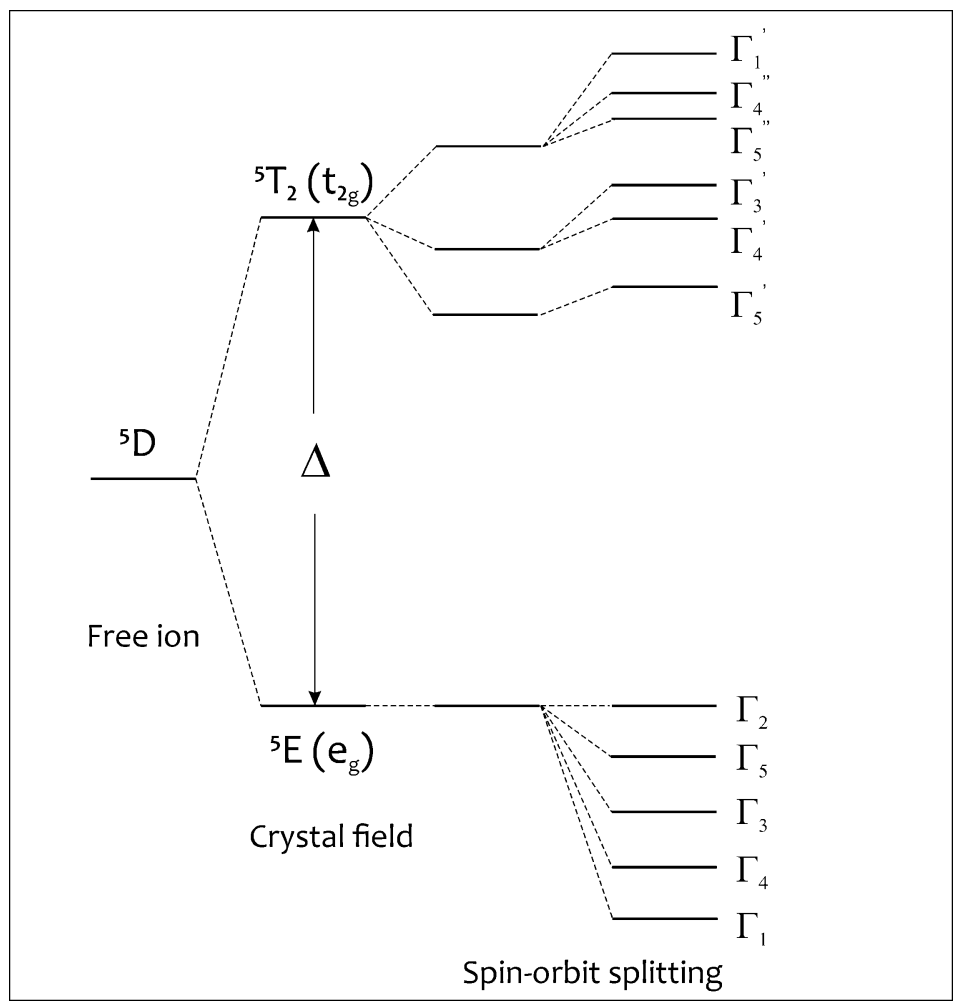


Figure 7.

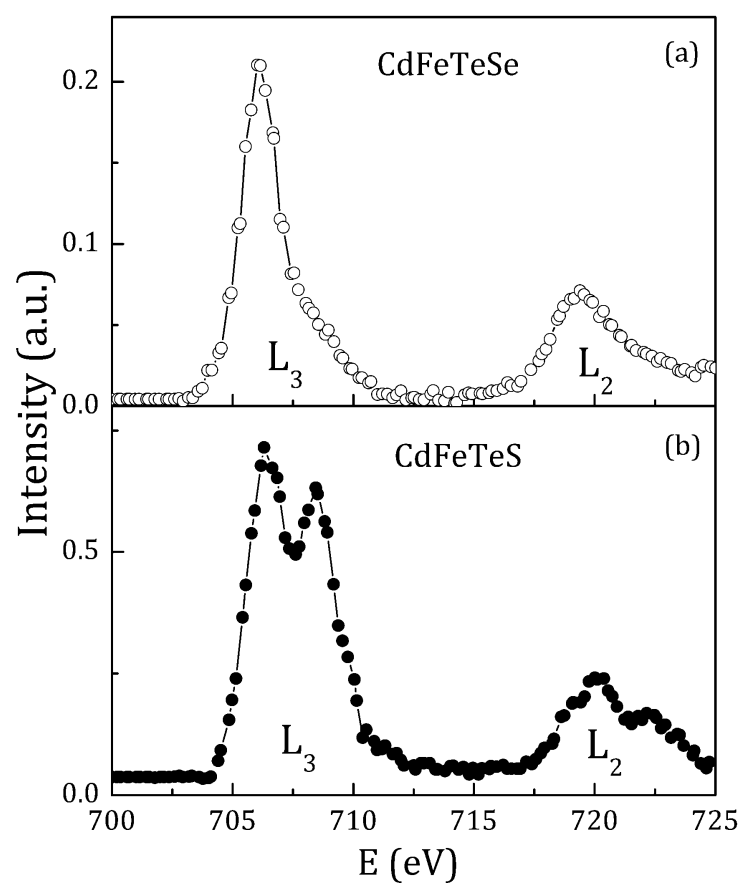

Figure 8.
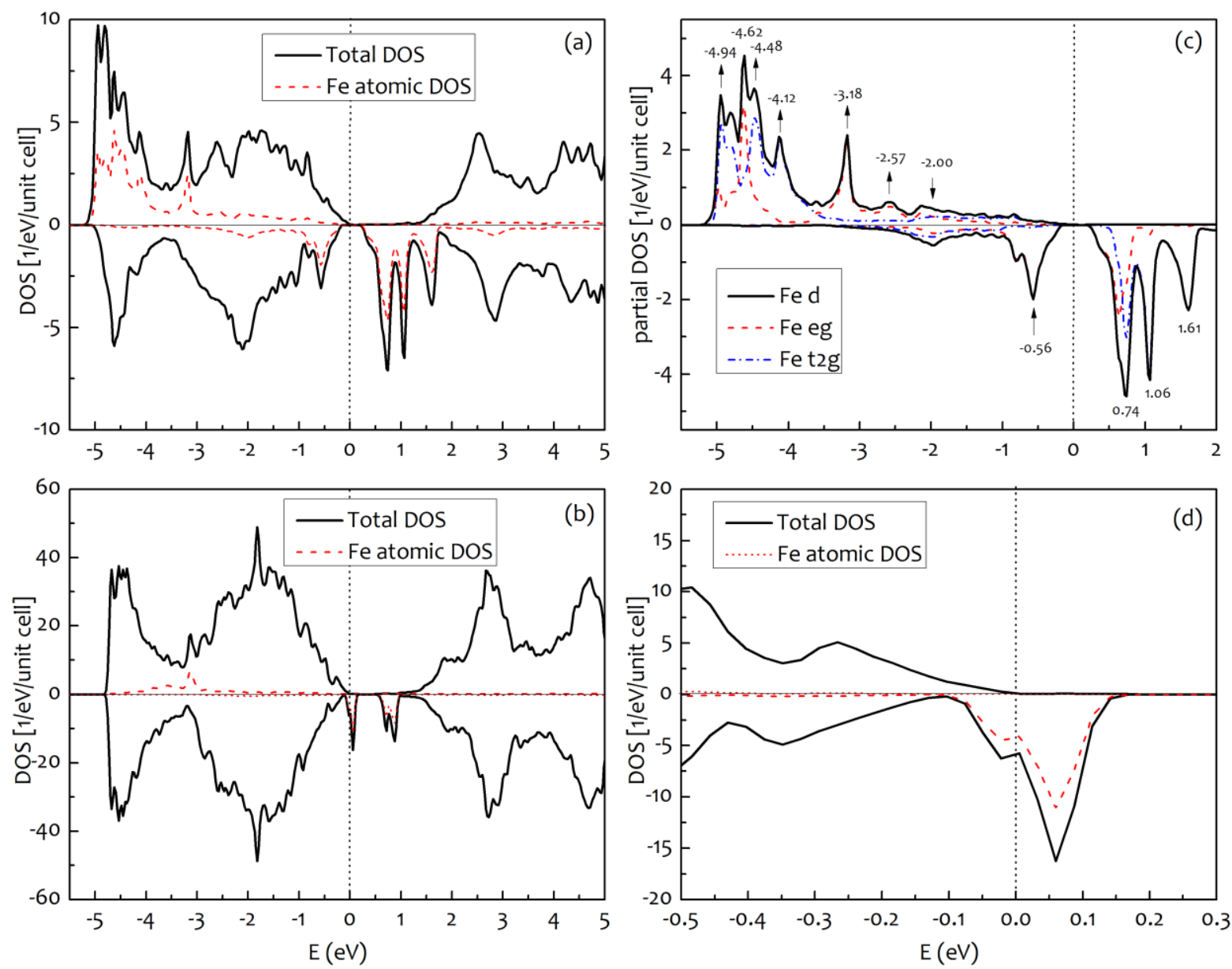